\title{
La ciudad un espacio de desencuentro social
}

Prof. Germán Rozas ${ }^{1}$

El tema que quisiera aportar en este Seminario, está relacionado con el fenómeno de la ciudad y por ello, me pareció válido titular mi presentación como : "La ciudad un espacio de desencuentro social". A propósito de esto voy a usar como referencia a la ciudad de Santiago, en cuanto simbólicamente es relevante en nuestro pais.

En primer lugar, quiero decir que yo nacien esta ciudad Santiago, hice por primera vez el amor en Santiago, aquí quedé cesante y seguramente me voy a morir en Santiago. Haciendo un simil, Itaca para Ulises era la ciudad más importante, porque en ella nació, y pese a que Ulises viajó por lugares maravillosos y tuvo grandes experiencias, él siempre volvió a Itaca, pese a que Itaca era una ciudad miserable e insignificante, casi no era una ciudad, sino un pequeño pueblo.

Comenzando a referirme al tema de la violencia, quisiera partir comentando una pequeña experiencia de un colega psicólogo extranjero que visitó nuestra ciudad y que durante su estancia decidiun dia invitarlo a conocer y pasear por el centro de Santiago. Paradójicamente nos encontramos con algunos actos de violencia que él mismo me hizo relevante, por ejemplo, nos pareció que se encontraban dos calles, Avenida Bernardo O'Higgins y la calle José Miguel Carrera, cuando precisamente esos próceres de la patria no eran precisamente amistosos; por otro lado también, tuvimos una impresión contradictoria con la calle Huérfanos, la cual nunca coincide con la calle Compañia (sic); y por otro lado, el Registro Civil está instalado precisamente en la calle Huérfanos (sic).

Igualmente hay algunas extrañas coincidencias que no quiero interpretar, el caso de una calle llamada Michel Petain, que como ustedes saben fue colaborador de la invasión nazi en Francia, y como decía paralelamente va de la mano con otra calle que casualmente se llama los militares, aquí en el sector oriente de la ciudad.
Con esta pequeña introducción, para poder ubicarnos en el contexto de lo que es la ciudad, quisiera plantear en primer lugar que la ciudad ha pasado a constituirse en un espacio de gran importancia, en todo el mundo, un espacio en el cual prácticamente la mayoria de la población del planeta vive en ciudades.

En el tercer milenio la ciudad va a ser lo más significativo que pueda existir en tanto asentamiento humano. Ha habido un flujo y un proceso importante de migración hacia las ciudades. De hecho en el año 1930, en América Latina, la ciudad solamente tenía el $30 \%$ de la población, sin embargo hoy dia los habitantes llegan al $70 \%$, incluso en cifras de nuestro país, la población que vive en las ciudades llega más allá del $80 \%$. Esto plantea un conjunto de agresiones y violencias.

La ciudad se ha transformado por su crecimiento y desarrollo en una especie de monstruo que devora y consume todo. Lo que devora, básicamente, son los espacios regionales, se devora las regiones, consume el agua, consume alimentos de regiones, consume minerales, etc. Un caso dramático es la ciudad de México que consumió toda el agua de su propio territorio, de modo que las napas subterráneas quedaron vacias y luego se produjeron serias inundaciones en la ciudad de México, pero sin embargo no bastando con esto, la ciudad tiene que conseguir agua de otras regiones; en este momento consigue el vital elemento de regiones de cerca 200 $\mathrm{km}$. de distancia produciendo verdaderas sequias en esos lugares.

Esta situación es bastante grave y este es un acto fundamentalmente de agresión a las poblaciones que viven en esas regiones. Los habitantes con población campesina, población rural, población minera, población de pescadores, etc. Impactada su región, ellos se empobrecen, sufren necesidades y carencias, son afectados por diversos problemas sociales.

\footnotetext{
${ }^{1}$ Depto. de Psicología, Universidad de Chile, grozas@abello.dic.uchile.cl
} 
La salida más recurrida frente a este flagelo es la migración a la ciudad. Entonces aqui hay un primer elemento de violencia y agresión sobre poblaciones que viven en espacios regionales y que se ven obligados a emigrar a la ciudad.

En segundo lugar quisiera plantear, que cuando estas poblaciones y estos segmentos llegan a la ciudad no son precisamente bien recibidos en elámbito urbano, la ciudad no está preparada para acogerlos. Se encuentran con una ciudad constituida por comunas ricas y comunas pobres, y precisamente lo que hacen los migrantes o "lo que les hacemos" es obligarlos a instalarse en las comunas pobres, como asimismo también a ubicarse bajo los puentes, al costado de las vias férreas, a instalarse a orillas de las industrias y empresas que muchas veces botan sus residuos industriales contaminantes y tóxicos en las cercanias del entorno; como seguramente Uds ya lo han visto recientemente en el Canal Las Cruces de la comuna de Pudahuel. De esa forma la población migrante comienza a vivir en la ciudad en muy malas condiciones de calidad de vida, sufriendo un conjunto de penurias de los cuales no son culpables.

Del mismo modo es una agresión el tipo de vivienda social que se construye para sectores pobres. Estas son viviendas absolutamente reducidas que se construyen masivamente, sin una adecuada articulación para la creatividad y otras necesidades comunitarias. El caso de Puente Alto, por ejemplo, es dramático. Puente Alto en el año 1992 tenía 250.000 habitantes, en elaño 1997 tiene 450.000 habitantes, es decir Puente Alto prácticamente ha duplicado su población, y a pasado a ser una comuna más grande que la ciudad de Valparaíso. Ahora, esta enorme cantidad de población que ha llegado a Puente Alto no puede ser atendida por una comuna pobre, con pocos recursos, con pocos servicios; lugares donde indudablemente existen muchos problemas de violencia interior.

En tercer lugar, otro tipo de agresión relevante y significativa tiene relación con la imposición cultural que ejerce la ciudad sobre la población migrante. Esta población de origen campesina, minera o étnico, indudablemente dispone de una forma diferente de ser, de otra cultura. Sin embargo cuando llegan a la ciudad son absorbidos, les cae encima la cultura dominante, se les impone una forma de ser que ellos no conocen, que ellos no alcanzan a comprender, que no alcanzan a vivir como algo propio, sino que más bien tienen que adaptar- se, tienen que ajustarse y tienen que ceder sus propias formas de vida.

Quisiera contar a propósito de eso un ejemplo. Hace algunos años atrás en elárea de la Psicología Comunitaria estuvimos trabajando en la Comuna de la Florida en uno de sus barrios pobres, y en el período de verano tuvimos la responsabilidad de realizar algunas entrevistas. Durante ese proceso observamos que reiteradamente varios niños entraban subrepticiamente a la escuela del lugary de cierta manera lo destruian, quebraban sus ventanas, robaban sus materiales didácticos, si podian se robaban una silla, o si podian se extraian una cañeria de los baños. Nosotros les preguntamos a los padres de estos niños ¿que sucedía que ellos mismo no se preocupaban al respecto?, ¿por qué no les decian algo?, entonces su respuesta era sorprendente: los padres "nosotros venimos del campo y queremos de alguna forma triunfar en la ciudad, pero no por nosotros, sino por nuestros hijos, que triunfen ellos, que logren integrarse, que ellos sean reconocidos y por eso los inscribimos en la escuela, pero resulta que al poco andar, nuestros hijos son calificados como no suficientemente inteligentes, que tienen problemas de aprendizaje, que tienen hiperkinesia, etc.".

No quiero con este ejemplo culpar a los profesores, ni al establecimiento educacional, pero si a un sistema, que está instadalo y que discrimina a estos niños, quienes, o desertan por mutuo propio, o son expulsados del colegio. Entonces, obviamente cuando los padres ven esta situación, cuando incluso el colegio imparte materias y contenidos que no son referidos a su propio mundo, a sus necesidades, a su cultura, se sienten distantes, se sienten rechazados, se sienten poco reconocidos y en definitiva cuando sus hijos le preguntan a sus padres, "puedo ir al colegio a hacerlo 'tira', vaya 'hága lo que quiera' si total me da lo mismo el colegio, no estoy niahi".

Bueno, la situación descrita de una u otra manera lleva a problemas de delincuencia, a la constitución de diferentes grupos que resisten, que bloquean el flujo cotidiano de la ciudad, surge el conflicto en elámbito urbano, uno entre tantos. Todo el tema de la contra- cultura, es decir, el tema de cómo aparecen jóvenes que elaboran una forma diferente de ser, de dialogar, una forma diferente de vivir. El tema de la delincuencia, yo creo, es el tema más delicado al respecto, de hecho entre el año 1997 - 1998 hubo un 12\% de aumento de la delincuen- 
cia. Una estudiante del Dpto de Psicología, Soledad Trivelli, quien hizo su memoria sobre el tema de la seguridad ciudadana en la comuna de Conchali; recogió antecedentes que permiten segmentar la comuna en tres partes: una zona segura, una medianamente insegura y otra absolutamente insegura. Toda la población, todas las casas y viviendas que viven colindantes con la zona insegura construyen altas murallas, altas rejas, ponen, si es posible y si sus medios lo disponen, alarmas, un perro, etc. es decir, ellos establecen una muralla, establecen una división entre la zona más segura o medianamente seguray la zona insegura.

Si esta situación la proyectamos al ámbito de la ciudad observaremos que ocurre un proceso similar: se habla de seguridad ciudadana, lo que se traduce en definitiva en contratar más policías, disminuir la edad de discernimiento de los jóvenes, en contratar o adquirir más bienes, vehículos y armas a objeto de ser usados en acciones de represión. En definitiva son murallas que se van construyendo en la ciudad, separando comunas de posición acomodada de otras comunas de mala situación económica, es decir, esta ciudad se va construyendo con separaciones, con divisiones, todo ello son actos de violencia y especialmente son actos de desencuentros, donde no es posible que exista un reconocimiento mutuo de distintos sectores sociales.

Uno podría preguntarse, encontrándonos ya en el inicio del tercer milenio, si acaso podríamos calificar nuestra ciudad como ¿moderna? o mejor dicho como ¿civilizada?. ¿Es este el desarrollo que buscamos con una ciudad autocustodiada y xenofóbica?

Para ir terminando y no ocupar mucho tiempo, quisiera plantear dentro de este diagnóstico algunas propuestas o lineas. En primer lugar, señalar el tema de la diversidad como una cuestión significativa y relevante. Nuestra realidad latinoamericana, nacional, e incluso comunal son mundos pluriétnicos, nuestras ciudades son multiculturales. Estas apreciaciones sólo recientemente se hacen consciente en distintos espacios. La autoridades, elEstado y nuestra historia no están precisamente centradas en reconocer esta multiculturalidad.

Entender que el tema de las culturas es un tema significativo y relevante. ¿Qué significa esto? Significa entender que la cultura contiene elementos y herramientas de crecimiento y desarrollo. Si una cultura se impone a la otra, evidentemente impide la diversidad y la riqueza que ello implica. En la naturaleza existe la bio-diversidad, esto es diferentes seres vivos que pueden cruzarse, que pueden intercambiar, produciendo mayor desarrollo y capacidad de ingerencia y adaptación en el medio ambiente. Igualmente en el medio social, existe una mayor riqueza en un país que puede reconocer sus distintas subculturas, estimulando la creatividad, los matices, la producción, otras alternativas de vida. Esto no ocurre en nuestras ciudades; la cultura dominante se impone, aplasta otras posibilidades y otras miradas, genera una pobreza social y cultural.

Aceptar otras culturas es comprender la existencia de otros mecanismos de aprendizaje, mecanismos de producción, mecanismos de comunicación y otras interpretaciones del mundo que son esenciales para la riqueza colectiva.

Quisiera proponer en este sentido el tema del interculturalismo, un concepto que hoy día interpreta estos fenómenos y que incluso va más allá del relativismo cultural. ¿Qué significa esto? Significa, en primer lugar, analizar las otras culturas según sus propios patrones culturales, es decir, un simil con la empatía. Sin embargo, también busca el cambio, como elemento de desarrollo, es decir cambio de aspectos negativos y fortalecimiento de dimensiones positivas. Pero dicha transformación no tiene sentido sino ocurre paralelamente en la propia cultura, en nosotros, por cuanto la riqueza de este proceso no una cuestión unilateral, en la medida que exista un contacto de un sector con otro sector, existe un cambio mutuo, interactivo, dialéctico y principalmente orientado a favorecer la relación entre culturas.

Por otro lado, se busca aquí un encuentro en igualdad, es decir que hable del no-paternalismo, de no superioridad y tampoco una inferioridad, en esta relación se trata también de tener una actitud crítica frente a las otras culturas. Las otras culturas, como la nuestra, no son culturas perfectas, cada cultura tiene su potencialidad y sus debilidades y en ese proceso se trata de fortalecer sus potencialidades.

Para terminar quisiera señalar que en torno a la ciudad se trata de transformarla en función de generar una verdadera civilización y eso significa un verdadero acercamiento cultural, una aproximación real entre distintos sectores, grupos, subculturas, culturas, de manera que en definitiva exista un encuentro en la diversidad.

Muchas Gracias. 


\section{Prof.LauraMoncada, Presentación de Rodolfo SapiainsyAndrésEcheverria}

Rodolfo y Andrés, ambos estudiantes egresados de la Carrera de Psicología de nuestro Departamento, trabajan en el Proyecto de Escuela Libre de la Barra "Los de Abajo".

Dada la Relevancia del fenómeno masivo del Fútbol y la grupalidad que lo rodea, asociada como imagen al despliegue de la violencia juvenil, es que Rodolfo y Andrés nos van a presentar reflexiones que han surgido desde la práctica de ser coordinadores y sujetos de esta experiencia. 